\title{
A combined model of sediment production, supply and transport
}

\author{
MASAHARU FUJITA ${ }^{1}$, KAZUKI YAMANOI ${ }^{2}$ \& HIROAKI IZUMIYAMA ${ }^{3}$ \\ 1 Disaster Prevention Research Institute, Kyoto University, Gokasho, Uji, Kyoto, 611-0011, Japan \\ fujita.masaharu.5x@kyoto-u.ac.jp \\ 2 Graduate School of Engineering, Kyoto University, Kyoto daigaku-katsura, Nishikyo-ku, Kyoto, 615-8530, Japan \\ 3 Public Works Research Institute, 1-6 Minamihara, Tsukuba-shi, Ibaraki, 305-8516, Japan
}

\begin{abstract}
In previous sediment-runoff models, the sediment production rates of mountain slopes, and the sediment supply rates to streams typically have been developed using empirical methods. A process-based model for sediment production and supply is, however, required for more exact simulations of sediment runoff. In this study, we develop a method to calculate the sediment production rate due to both freeze-thaw action and the sediment supply rate (i.e. erosion rate of talus). These numerical models were then connected to an existing sediment transport model. The integrated model presented here was applied to a small mountainous watershed. We found that the calculated sediment production rate was within the range of values typically observed for this region. Additionally, the estimated annual sediment discharge using the model agreed with observational results. Lastly, we found that the model can be used to qualitatively characterize typical features of the actual sediment routine in mountainous watersheds.
\end{abstract}

Key words sediment production; sediment supply; sediment transport; freeze-thaw action

\section{INTRODUCTION}

Estimation of sediment runoff is very important for river-related planning and management decisions. Consequently, several numerical models for sediment runoff have been proposed (Sunada \& Hasegawa, 1994; Egashira \& Matsuki, 2000; Takahashi et al., 2000). However, these models require the exact boundary conditions for sediment supplies to streams, and they rely on statistical or empirical methods to generate the boundary conditions. This makes it difficult to apply such models under exceptional conditions such as extreme rainfall events. Also, large volumes of observational data are required to ensure the accuracy of the boundary conditions for such models.

The conditions for sediment supply strongly affect the sediment production process, but calculation methods for sediment production and sediment supply have not been coupled in existing methods. So far, the sediment production process has been largely discussed in the context of fields such as geology, hydrology, hydraulics, and so on (Matsuoka, 1990; Wegmann et al., 1998; Fujita et al., 2005; Tsutsumi et al., 2007). Unfortunately, there are few equations available for estimating sediment production rates on mountainous slopes, such as the Universal Soil Loss Equation (USLE). Further, almost all of the models developed to date are based on semi-empirical or semi-physical methods. Hence, it also is difficult to apply these models to a wide range of meteorological conditions.

Runoff processes from headwaters in mountainous regions, to river mouths, can be categorized into three sub-processes: sediment production, sediment supply, and sediment transportation. Sediment production is defined as the generation of fresh soil through the weathering of bedrock, landslides, gully erosion, volcanic eruptions, and so forth. Izumiyama et al. (2012) argued that freeze-thaw action is an important process in the final stages of sediment production, and proposed a numerical simulation model that can estimate the amount of sediment production based on topographical, meteorological and geological data. Following sediment production in mountainous regions, the generated sediment forms talus deposits at the toe of slopes. These talus sediments can then be eroded by floods and moved into streams. This is defined as a sediment supply process. Subsequently, fluvial sediment transport occurs in various forms including bed load, suspended load, wash load and debris flows. This is defined as the sediment transport process.

The integration of three sub-process models may provide a more exact sediment runoff model. It also is important to employ more physically based sub-process models to develop an integrated model that simulates the actual processes that take place under wide meteorological conditions. In 
this study, we investigate the actual sediment runoff process in an experimental basin at the Hodaka Sedimentation Observatory, Kyoto University, Japan, and develop an integrated model to describe sediment runoff. The numerical simulation method for the sediment production process due to freeze-thaw action proposed by Izumiyama et al. (2012) was employed here. A talus erosion model was developed to simulate sediment supply. Then, an integrated sediment runoff model connected these sub-process models to a sediment transport model proposed by Egashira \& Matsuki (2000). Finally, the integrated model was applied to the experimental basin to evaluate its performance, and to verify the validity of the model results.

\section{INTEGRATED MODEL}

An integrated sediment runoff model was developed by combining sediment production, sediment supply and sediment transport sub-process models into a single basin model that was composed of unit channels and unit slopes. The basin model, three sub-process models, and integrated model are described below.

\section{Unit channel and unit slope basin model}

Egashira \& Matsuki (2000) analysed basin-scale sediment routines with a basin model composed of unit channels and unit slopes; this model is shown in Fig. 1. In this study the sediment-runoff model was constructed based on this basin model. In Fig. 1, a unit channel is defined as a section in the river between two adjacent confluence points. One of the points in the most upstream unit represents the upstream boundary of the river system, and that of the most downstream unit represents the downstream boundary of the river system. The upstream boundary was set at the point where the catchment area was $125000 \mathrm{~m}^{2}$. The two slopes that connect with both sides of a unit channel were defined as unit slopes. A unit channel was assumed to be straight and uniform. The grain size distribution is given for each unit channel. At the upper end of a unit channel, two flows merge, and the lower end of the unit was established immediately upstream of the next confluence point; that is, a unit channel includes the confluence at the upstream end and excludes the confluence at the downstream end. The unit slope was assumed to be a rectangular inclined plane. The angle was calculated as an averaged angle of the actual slope.

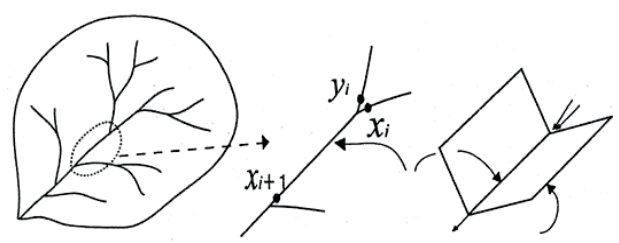

Fig. 1 Unit channels and unit slopes.

\section{Sediment production model}

Freeze-thaw action is one of the final stages of the bedrock weathering process. As a result of this action, the surface layer of weathered bedrock breaks up, and fresh soil remains on the slopes. Subsequently, wind, gravity, surface flows, and raindrops can remove the soil and displace it to the toe of the slope; thus, talus is formed at the sides of the channel. Considering the mechanisms of such a sediment production process, Izumiyama et al. (2012) presented a method for estimating the annual sediment production rate for different geologies. They classified the production rates into two groups for different types of bedrock, namely, those for soft bedrock (e.g. weathered granite, weathered granite porphyry, and weathered shale) and those for hard bedrock (e.g. weathered sandstone and weathered rhyolite). Figures 2(a) and (b) show conceptual sketches of the sediment production processes for soft and hard bedrock. In soft bedrock areas, sediment is generated by repetitive freeze-thaw action. Conversely, in hard bedrock areas, the surface exfoliates in thin layers whose depths correspond to the grain sizes of the produced sediment in each freeze-thaw cycle. Based on observational results (Tsutsumi et al., 2007), researchers have developed a relationship 


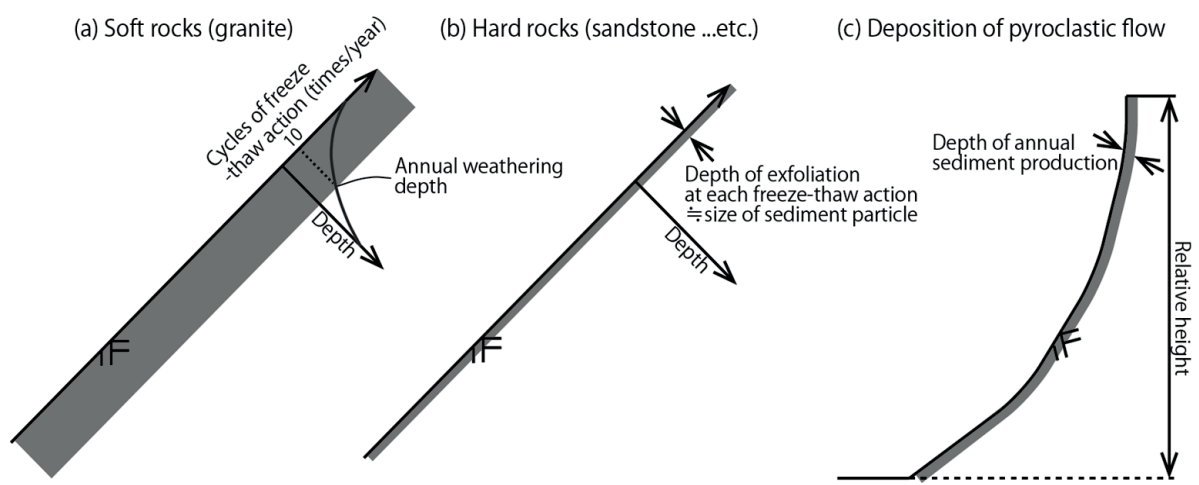

Fig. 2 Conceptual sketches of the sediment production processes on typical geological features.

between the sediment production rate and the vertical distribution of the number of repetitive freezethaw actions for soft rocks. As a result of these observations of sediment production, the critical number of repetitions was assumed to be 10 . Moreover, a relationship between the sediment production rate and the repetitive number of freeze-thaw actions on the surface of hard rocks was also obtained.

One of the major sediment sources in the experimental basin is the weathering of bare slope bedrock, and the main factor for sediment production is freeze-thaw action. Here, the method of Izumiyama et al. (2012) was employed for simulating sediment production from the weathering of bedrock located on bare slopes. The annual sediment production rate, which was expressed by the annual erosion depth, is described as follows:

$$
D_{j}=\left\{\begin{array}{lr}
f_{j}^{-1}(10) & \text { (Soft bed rocks) } \\
d m_{j} & \text { (Hard bed rocks) }
\end{array}\right.
$$

where: $D_{j}=$ the annual erosion depth expected on slope $j ; f_{j}(n)=$ the vertical distribution of the repetitive number $n$ of freeze-thaw actions for the year; $f_{j}^{-1}=$ the inverse function of $f_{j} ; d=$ the mean grain size of the sediment produced on slope $j$; and $m_{j}=$ the repetitive number of freeze-thaw actions on the surface of slope $j$.

The variables $f$ and $m_{j}$ can be calculated according to a numerical simulation method proposed by Tsutsumi et al. (2007). This method consists of the following equations for heat and water conservation under the slope surface:

$$
\begin{aligned}
& \rho_{G} C_{G} \frac{\partial T_{G}}{\partial t}=\frac{\partial}{\partial z}\left(\lambda_{G} \frac{\partial T_{G}}{\partial z}\right)+\rho_{i} L_{W} \frac{\partial \phi}{\partial t} \\
& \frac{\partial \theta}{\partial t}=C \frac{\partial \psi}{\partial t}=\frac{\partial}{\partial z}\left(K\left(\frac{\partial \psi}{\partial z}+1\right)\right)-\frac{\rho_{i}}{\rho_{w}} \frac{\partial \phi}{\partial t} \\
& S \downarrow-S \uparrow+L \downarrow=L \uparrow+H+l E+G
\end{aligned}
$$

where: $T_{G}=$ temperature below the slope surface; $\psi=$ pressure head; $\theta=$ water content; $\phi=$ ice content; $c_{G}=$ thermal capacity of bedrock; $\rho_{G}=$ density of bedrock; $\rho_{w}=$ density of water; $\rho_{i}=$ density of ice; $\lambda_{G}=$ thermal conductivity; $L_{w}=$ latent heat of ice; $C=$ water capacity function; $K=$ coefficient of permeability; $t=$ time; $z=$ axis perpendicular to the slope surface; $S \downarrow=$ downward shortwave emission (quantity of horizontal plane sunlight); $S \uparrow=$ upward shortwave radiation; $L \downarrow$ $=$ downward longwave radiation (atmospheric radiation); $L \uparrow=$ upward longwave radiation (Earth's radiation); $H=$ latent heat; $l E=$ evaporation latent heat; and $G=$ increasing rate in heat of the calculation domain. $l E$ can be neglected under conditions of low temperature. Using albedo, $S \uparrow$ is obtained with $S \downarrow$.

In the experimental basin, bare slopes connect with the channel, and they consist of a layer of unconsolidated pyroclastic flow deposits. Another major sediment source is the bare slopes shown 
in Fig. 2(c). Ashida et al. (1983) observed the process of sediment production in this field and obtained the following empirical equation for the sediment production rate based on the slope height:

$D_{j}^{\prime}=0.01 H_{j} \quad$ (Unconsolidated pyroclastic flow deposit layer)

where: $D_{j}{ }^{\prime}=$ the annual erosion depth on bare slope $j$ and $H_{j}=$ the height of bare slope $j$.

The annual sediment production rates $V_{1 j}$ (on the bare slope of weathered rock) and $V_{2 j}$ (on the bare slope of the unconsolidated pyroclastic flow deposit layer) are expressed as follows:

$$
\begin{aligned}
& V_{1 j}=S_{b j} D_{j} \\
& V_{2 j}=l_{g j} D_{j}^{\prime} \frac{H_{j}}{\sin \theta_{j}}
\end{aligned}
$$

where: $S_{b j}$ is the area of bare slope $j$ of weathered rock; $l_{g j}$ is the length of bare slope $j$ of the unconsolidated pyroclastic flow deposit layer; and $\theta_{j}$ is the inclination of the bare slope.

Information regarding both the amount and timing of sediment production is important for creating an accurate sediment runoff model. It seems reasonable to conclude that the timing of sediment production corresponds to the thawing time $t_{f t}$ when the surface temperature of the bare slope changes from minus to plus degrees Celsius. If a sediment production event takes place $n_{1 j}$ and $n_{2 j}$ times on the bare slope $j$ of the weathered rock and the unconsolidated pyroclastic flow deposit layer, respectively, the sediment production rates, on average, for each event are $V_{1 j} / n_{1 j}$ and $V_{2 j} / n_{2 j}$. This sediment is assumed to be produced at time $t_{f t}$.

\section{Sediment supply model}

The sediments produced at the sides of the channel form talus deposits, and the talus can be eroded during floods. This is a sediment supply process. Takahashi et al. (2001) have already proposed an erosion model based on the assumption that the erosion rate of talus is half the riverbed erosion rate. In this paper a simple erosion model is proposed considering the following processes.

A stream widens with flow discharge and erodes talus at the sides of the channel where the streamwater reaches the talus. The erosion rate is dependent on the shear stress on the submerged part of the talus; therefore, it is necessary to evaluate the shear stress. However, here, the submerged part of the talus simply was assumed to be eroded so that the stream width becomes a value that can be calculated by the regime theory.

Additionally, the talus and the stream were assumed to reflect the conceptual model shown in Fig. 3, where: $B_{v i}=$ the width of unit channel $i$ that is unique for each unit channel; $B_{c i}=$ the stream width in unit channel $i ; B_{s i}=$ the talus width in unit channel $i$; and $H_{s i}=$ the height of talus in unit channel $i$. In this model (Fig. 3), the stream and talus are located at the left-hand side and right-hand side of the unit channel, respectively. The slope angle near the channel was assumed to be 50 degrees and the slope of the talus surface was set to 35 degrees, that is, as the angle of repose for the sediment. The talus was assumed to be a triangular prism with a length of bare slope with a width of $l_{t i} . B_{c i}$ and follows equation (8) based on regime theory:

$$
B_{c i}=\alpha \sqrt{Q_{i}}
$$

where: $Q_{i}=$ the water discharge in unit channel $i$ and $\alpha=$ a coefficient. Sawada (1982) showed that this coefficient was 3.5 in an experimental basin. Sediment supply to talus at time $t$ through the sediment production process is calculated by equations (9) and (10) using equations (6) and (7):

$$
\begin{aligned}
& Q_{\text {proli }}(t)=\sum_{j=1}^{m_{i}}\left(V_{1 j} \frac{T_{1 j}(t)}{n_{1 j}}\right) \\
& Q_{\text {pro2i }}(t)=\sum_{j=1}^{m_{i}} V_{2 j} \frac{T_{2 i}(t)}{n_{2 i}}
\end{aligned}
$$


where: $m_{i}=$ the number of the bare slopes in the unit slope $i ; T_{1 j}$ and $T_{2 j}$ are variables that equal 1 at time $t_{f t}$ and 0 at any other time.

The talus volume per unit length $S_{g i}$ is expressed as follows:

$$
S_{g i}(t)=\frac{1}{l_{t i}}\left(\int_{0}^{t} Q_{\text {prop }_{b} i}(t) d t-\int_{0}^{t} Q_{\text {supi }}(t) d t\right)+S_{g i 0} \quad\left(p_{b}=1 \text { or } 2\right)
$$

where: $S_{g i 0}$ is the initial $(t=0)$ talus volume per unit length and $Q_{\text {supi }}$ is the sediment supply rate to the unit channel $i$, which can be calculated by equation. (12):

$$
Q_{\text {su } p i}(t)= \begin{cases}l_{t i} H_{s i}(t) \frac{d L}{d t} & \text { when } L>0 \\ 0 & \text { when } L \leq 0\end{cases}
$$

where: $L$ is a length defined as $L=B_{s i}(t)+B_{c i}(t)-B_{v i}$. $B_{s i}$ is calculated geometrically if the talus volume in unit channel $i$ is known. Because $B_{v i}$ is constant, $d L / d t=d B_{s i} / d t+d B_{c i} / d t$.

Using this model, the influence of the flood history and sediment production processes on talus growth can be simulated, and leads to a more accurate simulation of sediment runoff.

\section{Sediment transport model}

The sediment transport model of Egashira \& Matsuki (2000) was employed and linked to the sediment supply model. This model simulates the changes in bed elevation in the unit channel and in the grain size distribution of bed material. Rainfall runoff also was simultaneously simulated using the kinematic wave method and Darcy's law. The sediment mass estimated from the sediment supply model was placed on the nearest unit channel. The sediment deposition rate due to sediment supply is expressed as follows:

$$
\frac{d z_{i}}{d t}=\frac{Q_{\text {su } p i}(t)}{l_{i} B_{c i}}
$$

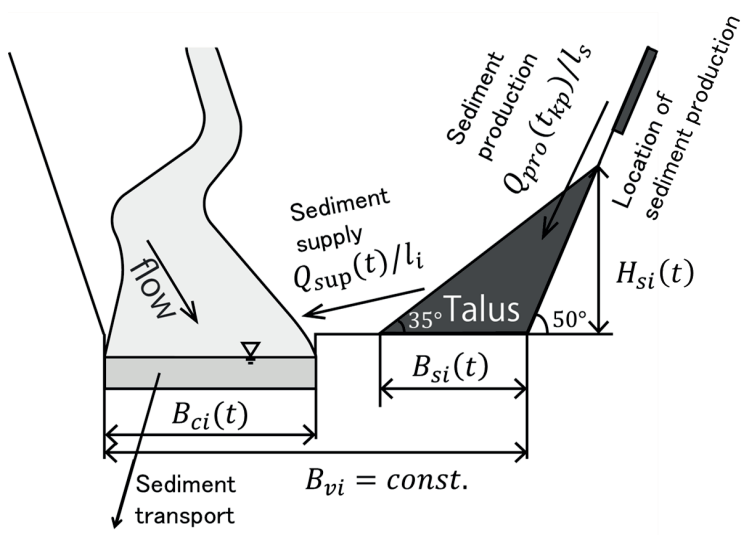

Fig. 3 Concept of the talus erosion model.

\section{Integration of the three models}

Figure 4(a) shows the method used to integrate the three sub-models described above; GRASS-GIS was employed for data processing. First, the positional information for unit channels and unit slopes was extracted from the DEM (digital elevation model) by GIS processing. The locations of the bare slopes of weathered rock were determined from aerial photos, and the locations of the bare slopes of the unconsolidated pyroclastic flow deposit layer were extracted by overlaying geologic maps on the unit-channel network. Next, using topographical and meteorological data, the sediment production rate and the timing of production were calculated and transferred to the sediment supply model. Third, the simulation of sediment transport was conducted using the simulation results for the sediment supply rate. 


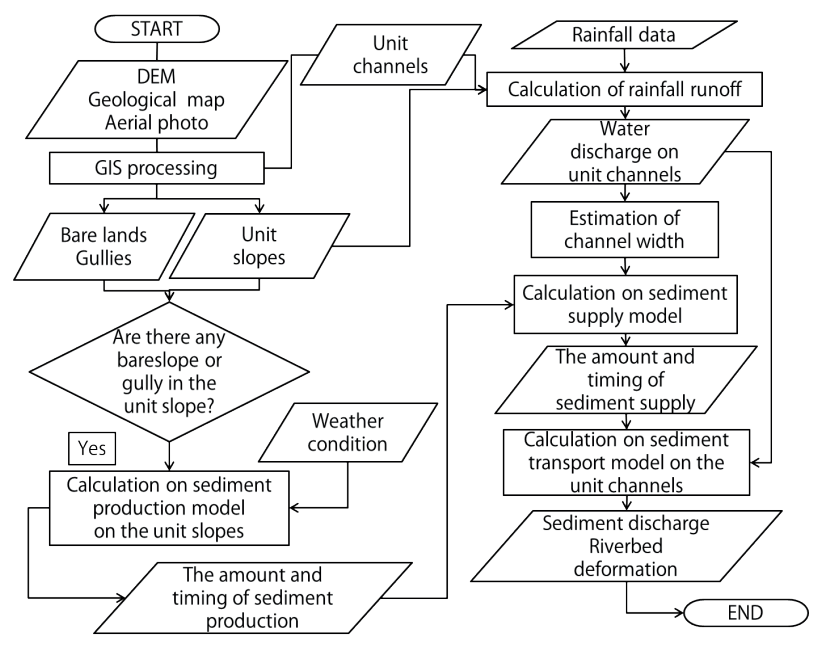

(a) Integration method for each model.

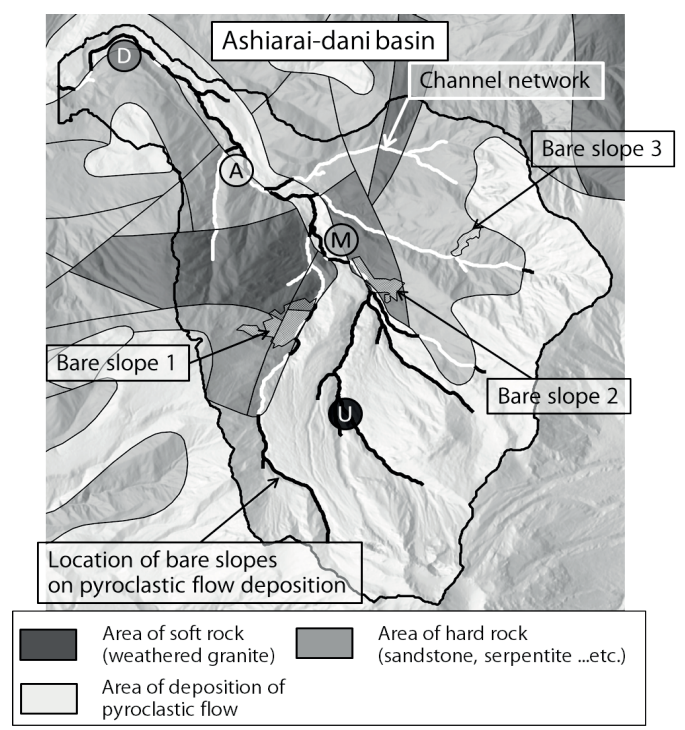

(b)

Fig. 4 (a) Integration method for each model. (b) Unit channels, categorized geological features, and sediment sources in the basin. Locations where calculation results were shown are denoted with circles.

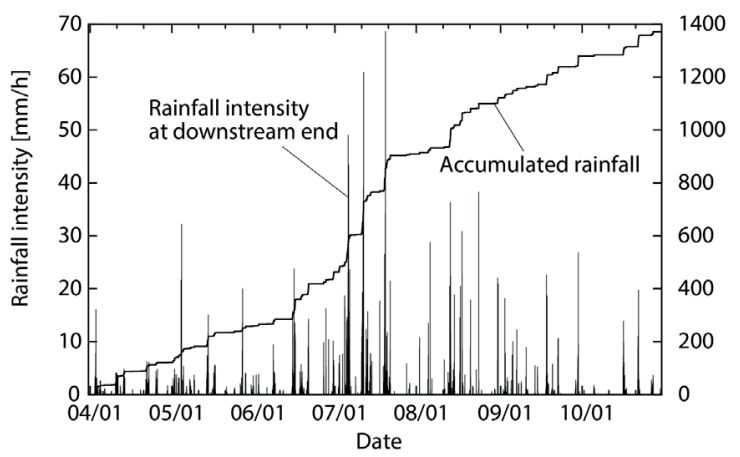

(a)

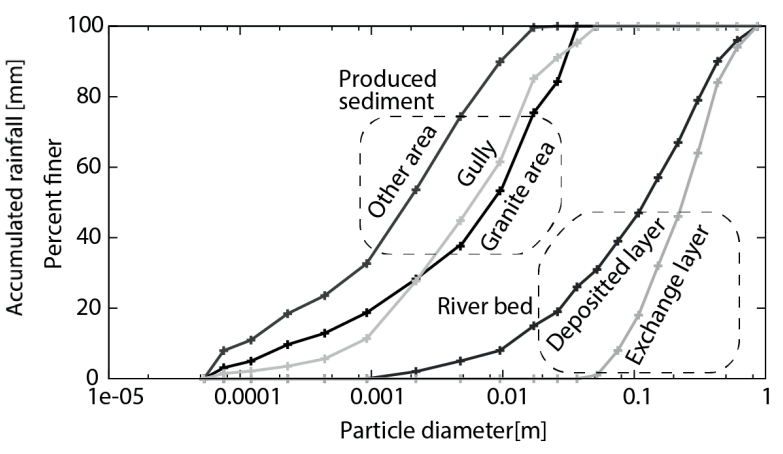

(b)

Fig. 5 (a) Rainfall data at the downstream end in 2012. (b) Grain size distribution in each geological feature.

\section{APPLICATION}

\section{Conditions}

The geologic map was overlain on this map. Because sediment movement is inactive in the winter season, only rainfall data from April to November 2012 were used for the simulations. Rainfall was observed by a C-band radar system such that the spatial distribution of precipitation was available. Figure 5(a) shows the change in rainfall intensity at the downstream end of the basin.

A dataset including meteorological data on temperature, solar radiation, wind velocity, and humidity from 2011 to 2012 was used for calculating the vertical distribution of temperature under the slope surface. The grain size distribution of the riverbed was a very important parameter in this calculation. The initial grain size distribution was obtained by pre-calculations for 5 years using rainfall data at a gauge station near the basin from 2007 to 2011. Figure 5(b) shows the grain size distribution from the pre-calculations.

\section{Calculation results and discussion}

Table 1 shows the calculated results for sediment production. The estimated total amount of sediment produced on the bare slopes was about $8300 \mathrm{~m}^{3} /$ year. The calculated specific sediment production was about $1100 \mathrm{~m}^{3} / \mathrm{km}^{2} /$ year, which is within the range of observed values for the Japanese central mountainous region (Ashida et al., 2008). 
Table 1 Calculation results for sediment production.

\begin{tabular}{llll}
\hline & $\begin{array}{l}\text { Geological feature } \\
\text { (primary) }\end{array}$ & $\begin{array}{l}\text { Area of land and } \\
\text { total length }\end{array}$ & $\begin{array}{l}\text { Amount of sediment } \\
\text { production per unit area }\end{array}$ \\
\hline Bare slope 1 & Hard rocks (serpentinite) & $73100 \mathrm{~m}^{2}$ & $0.017 \mathrm{~m} /$ year \\
Bare slope 2 & Soft rocks (granite) & $34375 \mathrm{~m}^{2}$ & $0.024 \mathrm{~m} /$ year \\
Bare slope 3 & Hard rocks (sandstone) & $13300 \mathrm{~m}^{2}$ & $0.013 \mathrm{~m} /$ year \\
$\begin{array}{l}\text { Bare slopes on pyroclastic } \\
\text { deposition (total) }\end{array}$ & Pyroclastic deposition & $\begin{array}{c}9223 \mathrm{~m} \text { (longit } \\
\text { udinal length) }\end{array}$ & $0.050 \mathrm{~m} /$ year \\
\hline
\end{tabular}

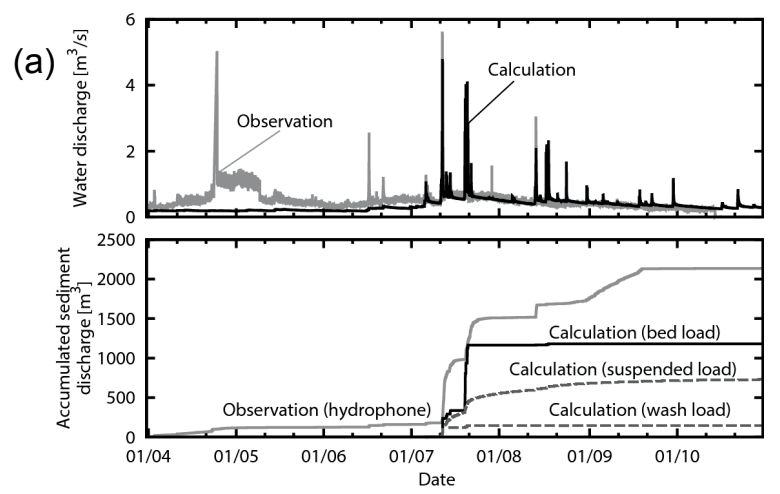

(b)

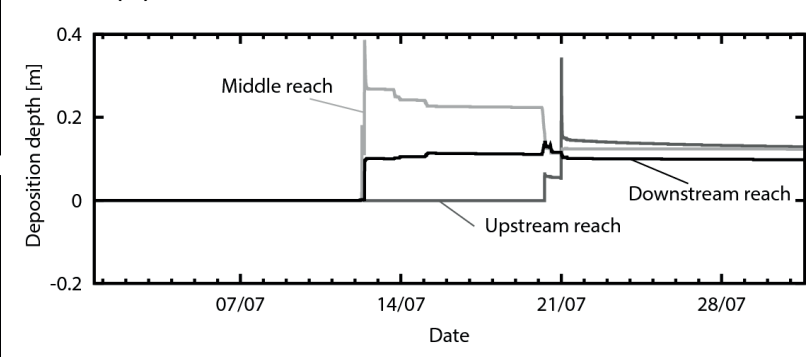

(c)

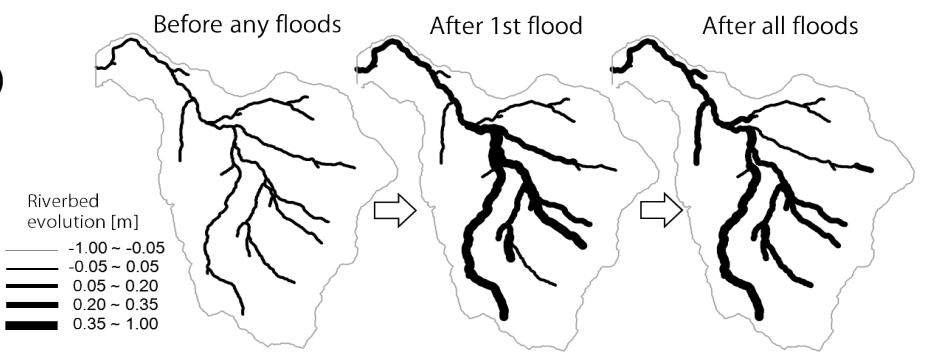

Fig. 6 (a) Calculation and observation results at Point A. (b) River bed evolution at three points in the basin. (c) Transition of deposition depth on the river bed.

Figure 6(a) shows the calculated and observed results of water and sediment discharge at Point A. The sediment discharge was observed with a hydrophone sensor (Tani et al., 2012) that can measure sediment discharge from a record of sound pressure. The calculated results for water discharge from April to June were relatively lower than the observed results. This is because water discharge from snowmelt was not considered in this model. However, the calculated results for water discharge had a relatively high accuracy from July to August, and these data were sufficiently robust to permit an evaluation of sediment discharge during the flood season in central Japan. The calculated cumulative sediment volume at Station A during the time period analysed was about $1200 \mathrm{~m}^{3}$, which was slightly less than the observed value; however, it fell within the measurement uncertainties associated with using hydrophone measurements.

Figure 6(b) shows the riverbed evolution at three different points which are shown on the map in Fig. 5(b). The riverbed at Point $U$ in the upstream reach rose suddenly after the sediment supply and immediately decreased because of the high tractive force. The riverbed aggradation here depended not on the transported sediment from upstream but on the sediment supply. In contrast, the riverbed evolution at the downstream reach (Point D) depended on sediment transport from upstream. At the middle reach (Point $\mathrm{M}$ ), the riverbed displayed complex changes because it was influenced by both sediment transport and sediment supply. In other words, our calculation results show that the characteristics of riverbed evolution differ depending on the distance between channels and sediment sources. This indicates that a specific characteristic of sediment runoff in mountainous watersheds is that the relation between sediment discharge and water discharge is not unique. Figure 6(c) shows the calculation results for sediment deposition in the basin on three different dates: 25 June (before any floods), 13 July (just after the first floods of the season), and the time at the end 


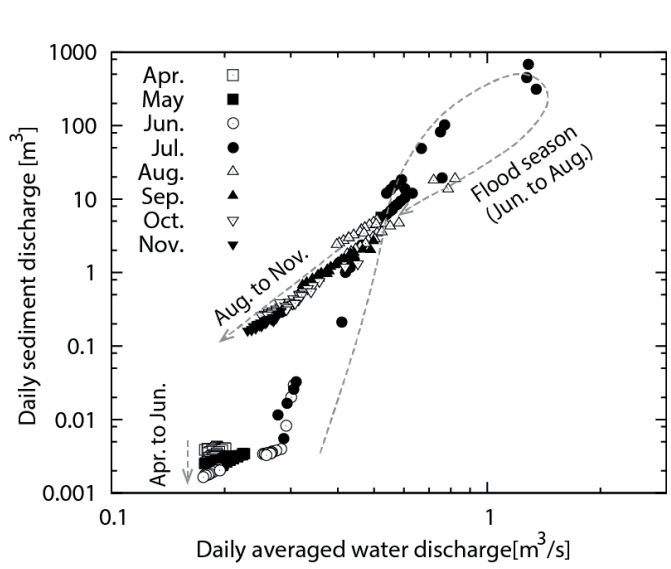

(a)

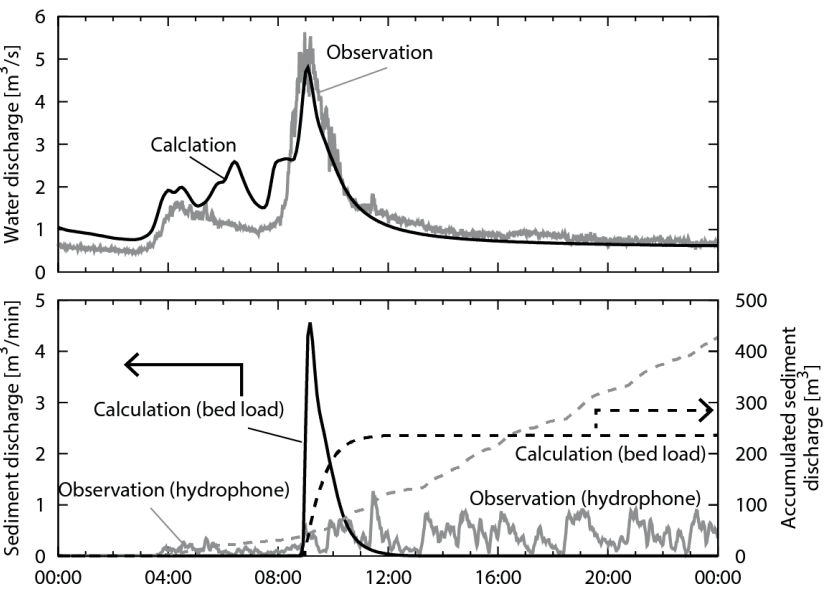

(b)

Fig. 7 (a) Seasonal variation of the sediment discharge. (b) Water and sediment discharge on 12 July.

of the calculations when flooding had largely subsided. Sediment deposition appeared because of the sediment supply when the first floods occurred, especially in the upstream end. Most of this supply remained temporarily, and then was flushed out after further flooding. After all floods of the year, the supplied sediment remained to some extent, and was rather evenly distributed.

Figure 7(a) shows the seasonal change of the relationship between water discharge and sediment discharge. The sediment discharge was relatively low from April to June. The sediment discharge rose suddenly in July because of the outstanding sediment supply, and then decreased from August to November because the talus was no longer being eroded. This result also is indicative of a characteristic of sediment runoff in mountainous watersheds; specifically, it indicates that the relationship between water discharge and sediment discharge depends on the timing of sediment production, sediment supply, and floods.

Figure 7(b) shows the sediment discharge during a rainfall event on 12 July. The calculated water discharge agreed very well with the observational results. However, the accumulated sediment discharge from the calculations only roughly expressed the same tendencies as the observational results. In particular, the observed sediment discharge increased gradually and the peak value was much smaller than the simulated one. The simulated sediment discharge increased suddenly with a high peak before decreasing rapidly. One likely reason for this trend is the effect of river morphology, such as step-pool bed formation, on sediment transport processes. It is thought that sediment storage in pools can delay transportation and smooth out time variations in sediment discharge.

\section{CONCLUSION}

Sediment runoff processes in mountainous watersheds begin with sediment production on bare slopes; then, the sediments form talus deposits along the stream banks. High stream flows such as those during floods erode the talus, and the sediments are supplied to the stream where they are transported further downstream. In this study, we developed three sub-process models for sediment production, sediment supply, and sediment transport, and proposed an integrated sediment runoff model. The integrated model was applied to a small mountainous watershed in Japan, and we found that some typical characteristics of sediment runoff in mountainous regions can be expressed qualitatively. For example, the model showed that sediment discharge is dependent on more than just water discharge, and that the relation between these outputs changed seasonally. Specifically, the sediment runoff process was also strongly dependent on the timing of sediment production, sediment supply, and floods. While the proposed sediment runoff model can be used to simulate annual sediment discharge reasonably well, it cannot be used to simulate short-term variations in sediment discharge. In particular, there were large differences in the peak sediment discharge and the duration times for active sediment transport. New ideas about how river morphology affects 
sediment transport will be necessary to improve the model; therefore, future work on model development will be forthcoming.

\section{REFERENCES}

Ashida, K., Takahashi, T. \& Sawada, T. (1983) Runoff process, sediment yield and transport in a mountain watershed (12). Annuals of Disaster Prevention Research Institute, Kyoto Univ. 26B-2, 303-314

Ashida, K., Egashira, S. \& Nakagawa, H. (2008) River Morphodynamics for the 21st Century. Kyoto University Press.

Egashira, S. \& Matsuki, T. (2000) A method of predicting sediment runoff caused by erosion of stream channel bed. Annual Journal of Hydraulics Engineering, Japan Society of Civil Engineers 44, 735-740.

Fujita, M., Sawada, T, Shida, M. \& Itoh, M. (2005) Characteristics on sediment production in the Takahara River Basin. Annual Journal of Hydraulics Engineering, Japan Society of Civil Engineers 49, 1075-1081.

Izumiyama, H., Tsutsumi, D. \& Fujita, M. (2012) Effect of freeze-thaw action on porosity change and destruction of weathered bedrock in different lithology and development of destruction model. International Journal of Japan Erosion Control Engineering 5(1), 103-112.

Matsuoka, N. (1990) The rate of bedrock weathering by frost action. Earth Surface Processes and Landforms 15, 73-90.

Sawada, T., Ashida, K. \& Takahashi, T. (1982) Variation on stream channel and sediment transport in mountain region. Proceedings of the Japanese Conference on Hydraulics 26, 105-110.

Sunada, K. \& Hasegawa, N. (1994) Study on a synthetic model for sediment routing in a mountainous river system. Journal of the Japan Society of Civil Engineers 485/II-26, 37-44.

Takahashi, T., Inoue, M., Nakagawa, H. \& Satofuka, Y. (2000) Prediction of sediment runoff from a mountain watershed. Annual Journal of Hydraulics Engineering, Japan Society of Civil Engineers 44, 717-723.

Takahashi, T., Inoue, M., Nakagawa, H. \& Satofuka, Y. (2001) Prediction of sedimentation process in a reservoir using a sediment runoff model. Annual Journal of Hydraulics Engineering, Japan Society of Civil Engineers 45, 841-846.

Tani, Y., Tsutsumi, D. \& Mizuyama, T. (2012) Evaluation of sediment transport characteristics and estimation of sediment sources based on sediment discharge monitoring. Journal of the Japan Society of Erosion Control Engineering 65(3), 21-28.

Tsutsumi, D., Fujita, M., Itoh, M., Teshima, H., Sawada, T., Kosugi, K. \& Mizuyama, T. (2007) Fundamental study on sediment yield due to freeze and thaw process. Journal of the Japan Society of Erosion Control Engineering 59(6), 3-13.

Wegmann, M., Gudmundsson, G.H. \& Haeberli, W. (1998) Permafrost changes in rock wall and the retreat of alpine glaciers. Permafrost and Periglacial Processes 9, 23-33. 